\title{
Nosotros hemos dejado nuestra juventud en este país. Experiencias laborales en la industria de la construcción estadounidense. El caso de trabajadores mexicanos en Carolina del Norte
}

\section{MARÍA LETICIA RIVERMAR PÉREZ}

> Instituto de Ciencias Sociales y Humanidades de la Benemérita Universidad Autónoma de Puebla. Irivermar@gmail.com

Universidad de Valparaíso

Facultad de Arquitectura

Revista Márgenes

Espacio Arte Sociedad

Nosotros hemos dejado nuestra juventud en este país. Experiencias laborales en la industria de

la construcción estadounidense. El caso de trabajadores mexicanos en Carolina del Norte

Diciembre 2013 Vol. $10 \mathrm{~N}^{\circ} 13$

Páginas 40 a 48

ISSN elec. 0719-4463

ISSN imp. 0718-4034

Recepción: Agosto 2013

Aceptación: Diciembre 2013

RESUMEN

En el contexto de los nuevos procesos de proletarización gestados por el modelo de acumulación flexible de capital, desde los años 80 se observa un incremento exponencial de los desplazamientos de trabajadores mexicanos hacia nuevos destinos en Estados Unidos. En este trabajo, analizamos la inserción precaria en la industria de la construcción de Carolina del Norte de varones en edades productivas originarios del municipio de Pahuatlán, Puebla, en el centro de México. El estudio se sustenta en entrevistas a profundidad, llevadas a cabo entre 2007-2012 en Pahuatlán y en la ciudad de Durham en octubre de 2013.

PALABRAS CLAVE

migración de trabajadores mexicanos a Estados Unidos, nuevos procesos de proletarización, industria de la construcción estadounidense

We have left our youth in this country. Work experience in the U.S. construction industry. The case of Mexican workers in North Carolina ABSTRACT

In the context of the new processes of proletarianization gestated by flexible capital accumulation model, since the 80 s is observed an exponential increase in the movement of Mexican workers to new destinations in the United States. In this paper, we analyze the precarious inclusion in the construction industry of North Carolina of males in productive ages originating from Pahuatlán Township, Puebla, in Central Mexico. The study is based on in-depth interviews, carried out between 2007-2012 in Pahuatlán and the city of Durham in October 2013. KEYWORDS

migration of Mexican workers to the United States, new process of proletarianization, the U.S. construction industry

Nous avons laissé notre jeunesse dans ce pays. Expérience de travail dans le secteur du bâtiment américain. Le cas des travailleurs mexicains en Caroline du Nord

RÉSUMÉ

Dans le contexte du nouveau processus de prolétarisation utilisé par le modèle d'accumulation flexible du capital, depuis les années 1980 il s'observe une augmentation exponentielle dans les déplacements des travailleurs mexicains vers de nouvelles destinations aux États-Unis. Dans cette recherche, nous analysons l'inclusion précaire dans le secteur du bâtiment de la Caroline du Nord des hommes en âge productif originaires de la municipalité de Pahuatlán, Puebla, au centre du Mexique. L'étude repose sur des entretiens approfondies, menées entre 2007 et 2012 à Pahuatlán et dans la ville de Durham en octobre 2013. MOTS CLÉS migration de travailleurs mexicains aux États-Unis, nouveau processus de prolétarisation, secteur du bâtiment aux États-Unis

40 > Revista Márgenes N 13 Vol. 10 > Diciembre 2013: 40-48 
El país [Estados Unidos] no hubiera crecido tanto si no fuera por el trabajo de los latinos.

[Aquí] los latinos siempre vamos a ser los trabajadores.

RUBÉN, Durham, NC, 9 de octubre de 2013

\section{INTRODUCCIÓN}

Tal como lo ha señalado David Harvey en su magistral obra The New Imperialism (2003:101), en aras de satisfacer su perpetua sed de acumulación el capitalismo constantemente busca crear un paisaje que facilite sus actividades, así, en un momento dado destruye un entorno para tiempo después construir uno diferente. Esta idea nos permite entender la metamorfosis del paisaje del sureste estadounidense, caracterizado hasta mediados del pasado siglo por grandes plantaciones agrícolas y un bajo desarrollo económico. Una oferta relativamente abundante de mano de obra tradicionalmente contraria a la organización sindical, suelo urbanizable, exenciones fiscales y otros incentivos atrajeron inversiones nacionales y extranjeras posibilitando que la expansión económica de la zona entre 1977 y 1992 superara la de cualquier otra región de Estados Unidos. A decir de Harvey (1998:170-171), la emergencia de nuevos conglomerados industriales en los años 70 y 80 en regiones que carecían de tradiciones industriales previas, responde al paso de un régimen de acumulación rígido a uno flexible.

La reubicación en las inmediaciones del sureste estadounidense de plantas procesadoras de alimentos, industrias carpeteras y automotrices (Mercedes, Honda, Hyundai), importantes centros financieros y de investigación, destacadas universidades (Duke University, The University of North Carolina at Chapel Hill) y laboratorios farmaceúticos (Bayer, Novartis), tuvo como correlato la inversión de capital fijo en tierra y en la construcción de fábricas, oficinas, viviendas, hospitales, escuelas, laboratorios e infraestructura para transporte y comunicaciones (Tinley, 2008; Levin y LeBaron, 2011). Este inusitado crecimiento económico coadyuvó a una potencial demanda de fuerza de trabajo para llevar a cabo empleos de baja remuneración en la manufactura, la construcción, la limpieza y el mantenimiento, que los trabajadores locales no estaban tan dispuestos a realizar (Levin y LeBaron, 2011). El sector de la construcción, que no tenía la opción de trasladarse al sur de la frontera en búsqueda de mano de obra barata, se vio obligado a "importar" fuerza de trabajo de países latinoamericanos, especialmente de México y Centroamérica. Estos trabajadores rápidamente se convirtieron en una mano de obra dócil, en disposición de laborar duro devengando bajos salarios, en condiciones de alto riesgo y de la que los empleadores podían deshacerse con facilidad (Levine y LeBaron, 2011).

Desde 1970 el empleo en la industria de la construcción estadounidense se duplicó hasta alcanzar su punto máximo de 7,7 millones en 2006: entre 2002 y 2006 se incrementó de 1,3 millones y cayó a 5,5 millones en 2010, antes de un ligero aumento (Byun, 2010; Martin, 2012). A excepción de la agricultura, este sector tiene una mayor proporción de trabajadores latinoamericanos o de ese origen que cualquier otro. Mientras el número de personas en el mercado laboral estadounidense que se identificaron como "hispanos", creció $120 \%$ entre 1980 y 2000 , en la industria de la construcción esta cifra se incrementó $150 \%$, es decir cuatro veces ${ }^{1}$; en 2007 el 16,2\% del total de trabajadores mexicanos en Estados Unidos laboraba en la construcción ${ }^{2}$. Es interesante anotar que los trabajadores latinos de esta industria son más jóvenes que otros: mientras la mayoría de los no hispanos se ubican en el grupo de edad de 45 a 49 años, los hispanos están en el grupo de 30 a 34 años (Martin, 2012).

Alrededor del $40 \%$ de la fuerza de trabajo en la construcción se concentra en la construcción residencial, grupo en el que la ocupación creció muy rápido antes del pico de 2006: la mitad de los 1,3 millones de empleos que se crearon entre 2002 y 2006 fue en la construcción residencial (Byun, 2010; Martin, 2012); entre mayo de 2006 y mayo de 2010 el empleo en ese grupo cayó 42\% (Cover, 2011). En esa coyuntura, aproximadamente 363.000 latinoamericanos perdieron sus empleos en 2007 y entre ese año y 2009 la participación de mexicanos cayó de 16,2 a 12,4\% (Kochhar, 2008; Parra y Gámez, 2012). Tal como lo ha señalado Martin (2009:648), a diferencia de lo que ha ocurrido en las industrias manufacturera, hotelera y restaurantera, en donde los empleadores enfrentaron la crisis reduciendo horas de trabajo con la esperanza de que la demanda se recuperara pronto, en la construcción muchos puestos fueron cancelados.

En este trabajo documentamos las condiciones laborales de trabajadores mexicanos insertos en la industria de la construcción estadounidense a partir del estudio de casos de migrantes originarios del municipio de Pahuatlán, localizado en la Huasteca poblana, ubicada en el noroccidente de la Sierra Norte del estado de Puebla, entidad del centro de México. La migración contemporánea a Estados Unidos en Pahuatlán se remonta a fines de los años 70 de la pasada centuria, cuando un puñado de hombres de la comunidad otomí de San Pablito Pahuatlán fue alentado por paisanos del vecino estado de Hidalgo a desplazarse a Texas en donde se emplearon en granjas avícolas y ranchos criadores de equinos. A inicios de la década de los 90, cuando los sanpablitos ya se habían establecido en zonas urbanas de Carolina del Norte, mayoritariamente en la ciudad de Durham ${ }^{3}$, a este flujo se sumaron mestizos de Pahuatlán de Valle, cabecera del municipio. Entonces el empleo en la industria de la construcción se convirtió para unos y otros en su principal fuente de ingresos. Tanto en San Pablito Pahuatlán (D'Aubeterre y Rivermar, 2011), como en Pahuatlán de Valle (D'Aubeterre y Rivermar, en prensa) alrededor del 50\% de los varones con experiencia migratoria internacional han laborado en ese sector de la economía estadounidense.

El escenario de los desplazamientos a Estados Unidos de pahuatecos y otomíes fue, por un lado, el desmantelamiento de la agricultura mexicana en el contexto de los ajustes estructurales de corte neoliberal y, por otro, la relativa pérdida de importancia de la Zona Metropolitana de la Ciudad de México como concentradora de población (Rubio, 1994; Reina y Luque, 1992). Hasta los 80 la economía de Pahuatlán tuvo como eje articulador la producción de piloncillo, cacahuate, café y diversos frutales; asimismo, el comercio y el trabajo asalariado en la agricultura intensiva de regiones colindantes, la industria textil y automotriz, los servicios y comercios, la construcción y labores de estiba en las grandes centrales de abasto de las ciudades aledañas, proveyeron de ingresos a los hogares del municipio. El desmantelamiento de la empresa paraestatal INMECAFÉ ${ }^{4}$ en 1989 fue la estocada de muerte de la economía regional y el propulsor de una migración masiva y acelerada al coloso del norte (D'Aubeterre y Rivermar, 2011).

Este flujo está conformado, mayoritariamente, por hombres en edades productivas que, ante la cancelación de sus posibilidades de reproducción y las de sus hogares a nivel local y nacional, cruzaron la 
frontera norte de México sin la requerida documentación migratoria (D'Aubeterre y Rivermar, 2011). Tal como lo hemos anotado en otros trabajos (D'Aubeterre, Rivermar y Binford, en prensa), entendemos que los campesinos y trabajadores "expulsados" o "excluidos" del mercado laboral mexicano, son "incluidos" en el mercado laboral estadounidense, donde la reestructuración económica generó una alta demanda de mano de obra barata en la construcción.

A partir del análisis de algunas entrevistas a profundidad de las varias docenas recopiladas en trabajo de campo llevado a cabo en los últimos seis años en el municipio de Pahuatlán y en Durham, Carolina del Norte en octubre de 2013, analizamos las condiciones laborales de trabajadores mestizos y otomíes empleados en la industria de la construcción de aquel estado de la unión americana. Entre otros temas, analizamos su precaria inserción laboral; los altos grados de explotación a que son sometidos sobre la base de su condición de migrantes indocumentados, de formar parte de una minoría étnica y de sus bajos niveles de escolaridad; asimismo, describimos las formas y redes de reclutamiento y sus riesgosas condiciones laborales.

\section{PAHUATECOS Y SANPABLITOS EN LA INDUSTRIA DE LA CONSTRUCCIÓN ESTADOUNIDENSE}

La incorporación de pahuatecos y sanpablitos al mercado laboral estadounidense se caracteriza por la extrema precariedad impuesta tanto por su situación de ilegalidad, como por el racismo que enfrentan en Estados Unidos; su ingreso relativamente reciente en ese mercado de trabajo y el que cubran espacios abandonados por la fuerza de trabajo convencional, han propiciado su ubicación en "mercados laborales secundarios" (Cooper, citado en Lara, 1998:107). En consonancia con lo documentado por Iglesias (2012) entre trabajadores latinoamericanos de la industria de la construcción española, pahuatecos y sanpablitos se incorporan a esa industria en el sureste estadounidense [...] como trabajo flexible, abundante y disponible que, además, de estar ligado a los segmentos más débiles de la miríada de cadenas de subcontratación del sector, desempeña algunas de las tareas más duras, pesadas y rutinarias (Iglesias, 2012:42).

Son "mano de obra de ejecución" que se ubica dentro de procesos y relaciones productivas y laborales fuertemente fragmentadas, su trabajo, como décadas atrás el de los obreros en la línea de montaje fordista (Harvey, 1998:156), se reduce a operaciones simples, sin ninguna calificación o saber productivo (Iglesias, 2012:46), lo que permite establecer jerarquías entre los trabajadores que se apoyan en distintas formas de discriminación o "minorización" (Lara, 1998:122). Tal es el caso de las ocupaciones que pahuatecos y sanpablitos realizan en la industria de la construcción estadounidense: cementero o ladrillero, pipelayer o paipero, freimero, chirroquero, rufero, pintor, carpetero, carpintero, plomero, electricista; también llevan a cabo labores de limpieza, mantenimiento y jardinería. Todas labores que no requieren conocimientos previos ni calificación alguna o muy baja calificación ${ }^{5}$, por lo que pueden ser realizadas por aquellos dispuestos “a aprender rápido y a echarle muchas ganas".

La incursión de trabajadores latinoamericanos en la industria de la construcción del sureste estadounidense evidencia el reemplazo étnico que en este nicho laboral se ha venido dando en los últimos años en aras de aumentar exponencialmente las ganancias de los empresarios. Puedo aventurar que estos trabajadores han sustitui- do a trabajadores nativos blancos, pues pareciera que la población afroamericana ha sido marginal en esa rama (Griffith, 2002); entre los otomíes y pahuatecos asentados en Durham corre la versión de que "Ios morenos no duran [en la construcción] porque no les gusta el trabajo pesado. Lo que les gusta es trabajar menos y ganar más. A las diferencias étnico-raciales entre los mexicanos y la población estadounidense (blancos y afroamericanos), se suman las diferencias entre indios y no indios que han caracterizado la historia de Pahuatlán y que se reproducen en esos escenarios laborales internacionales. Estas distinciones propician, entre otras cosas, que en las ocupaciones de pintores, limpieza, mantenimiento y jardinería los otomíes estén sobre-representados. Muchos mestizos menosprecian esos trabajos, a los que consideran un paso inicial en su trayectoria laboral dentro de la industria de la construcción. Piensan que son ocupaciones en las que permanecen quienes son incapaces de aprender o las ven como opciones marginales cuando el trabajo escasea y de las que hay que salir a la brevedad posible para re-incorporarse a aquellas actividades en las que se devengan mejores salarios. Podemos decir que estos sesgos étnico-raciales son aprovechados por los empresarios para acrecentar los grados de explotación y, con ello, sus ganancias.

\section{EL QUE NO TIENE DINERO Y LLEGA A TENER, LOCO SE QUIERE VOLVER. ENTRE LA CONCIENCIA DE LA EXPLOTACIÓN Y EL DESEO DE SUPERACIÓN}

La característica desregulación de las relaciones laborales de pahuatecos y sanpablitos propicia largas jornadas que dependen de la demanda, marcada por la temporada -en invierno el trabajo baja-y, en los últimos años, por la crisis del sector inmobiliario. Rigoberto, joven pahuateco de 29 años de edad, quien vivió en Estados Unidos entre 2002 y 2009, en donde se ocupó en la industria de la construcción en Carolina del Norte, Carolina del Sur y Nevada, describe con claridad los altos grados de explotación a que los trabajadores de esa industria se ven sometidos a partir de la modalidad de "trabajo a destajo":

[...] En Durham es difícil porque ahí sí es más pesado. Ahí entrábamos a trabajar [...] a veces a las 4 ó 5 de la mañana y regresábamos a las 10 de la noche. Como trabajas con puros contratistas ellos te explotan, [...] porque llegan y te dicen "te voy a dar 800 dólares por esta casa si la terminas en dos días". Uno va a hacer dinero y se queda uno desde temprano hasta la noche, porque a fin de cuentas estás trabajando por destajo, asi se le dice, por pieza, por una casa. Ellos te dicen de plano: "yo te doy tanto, si tú quieres meter a otra persona de más pues tú le pagas de tu dinero". Sí, asi [...] se va haciendo la cadenita hasta que llegan a uno, pero pues [...], al final de cuentas, haciendo la comparación de pesos mexicanos a dólares, pues sí le conviene a uno, porque, pues aquí ¿quién te da 8.000 pesos en una semana? Claro, no te queda todo, pero, por decir, de esos 8.000 pesos que ganas, son 3.200 dólares al mes, con 800 pagas tu renta, pagas todo [...]. Si ahorras te estás trayendo un promedio de 2.400 dólares al mes. Pero es como todo, también allá, ora sí como dice el dicho: "el que no tiene dinero y llega a tener, loco se quiere volver". Es que tienes allá a manos Ilenas todo, llevas una vida que aquí no [tienes] (Rigoberto, Pahuatlán de Valle, 13 de julio de 2011).
42 > Revista Márgenes № 13 Vol. 10 > Diciembre 2013: 40-48 Facultad de Arquitectura > Universidad de Valparaíso
$>$ ISSN electrónico 0719-4436 > ISSN impreso 0718-4034 
En un reporte del Job Bank USA ${ }^{6}$ se anota que en 2002 el salario mínimo de un trabajador de la construcción de edificios no-residenciales era de 12,97 dólares la hora y el de un trabajador de la construcción de edificios residenciales de 11,42. Estas diferencias salariales ${ }^{7} s e$ han acrecentado con la llegada masiva de trabajadores indocumentados, quienes comúnmente realizan trabajo a destajo. Así, el salario que Rigoberto devengaba, probablemente a mediados de la pasada década, se ubicaba muy por debajo del salario mínimo establecido en 2002: si dividimos los 800 dólares devengados entre 90 horas de trabajo durante seis días, resulta que su salario era de 8,88 dólares la hora. Pareciera que las pérdidas ocasionadas por la aguda contracción del sector han sido cargadas por los trabajadores migrantes, lo que además ha posibilitado que la industria empiece a mostrar signos de recuperación, especialmente aquellas empresas que se dedican a la construcción de edificios residenciales ${ }^{8}$. Pacheco y Morfín (en prensa) han señalado que el trabajo a destajo entre los jornaleros agrícolas en México, es una estrategia que incrementa exponencialmente las ganancias de los empleadores y la súper-explotación de los trabajadores. Estrategias como el trabajo a destajo - dicen estos autores- no son privativas del neoliberalismo, ni de la producción agrícola, han estado ligadas históricamente a la sobreexplotación del trabajo; sin embargo, se potencian bajo los nuevos esquemas de acumulación.

Una vuelta de tuerca más en los altos grados de explotación a que son sometidos pahuatecos y otomíes en la industria de la construcción está dada por los frecuentes abusos que sufren. Así, por ejemplo, tal como ocurre en otros espacios laborales, el costo de dañar material de trabajo corre por cuenta de los trabajadores, quienes, como lo relata Rigoberto, echan mano de argucias para evadir los gastos de reposición que repercutirían directamente sobre sus bajos salarios: A veces te llega el material contado. Si, por ejemplo, te llega una pieza que es cara y [si] la llega uno a echar a perder la repone uno, o vas a una construcción y te la llevas, te la robas, y dejas la que echaste a perder (Rigoberto, Pahuatlán de Valle, 13 de julio de 2011). Asimismo, la experiencia de los impagos es cotidiana en las vidas laborales de pahuatecos y sanpablitos. Miguel, otomí de 32 años de edad, originario de San Pablito Pahuatlán, con un historial de cinco viajes a Estados Unidos y quien al momento de la entrevista tenía menos de dos meses de haber regresado al pueblo, refiere con lujo de detalles los abusos de que fueron presas en 2012 él y otros trabajadores a quienes había sub-contratado:

[...] a mí me tocó no sé si la suerte o la mala suerte de toparme con un señor, con un americano, [que] me propuso trabajar, le trabajé. Me dejó como encargado de un trabajo grande, era la cafetería de una universidad nueva. Me propuso [...] que consiguiera yo gente pa trabajarle, [...] conseguí unos amigos para trabajar, éramos cuatro. Le trabajé cinco semanas, al principio sí me pagaba [pero] al final no me pagó; en la primera semana de que no hubo paga, como yo tenía un ahorrito, pues dije: "le pago a ellos y me pongo al parejo cuando me paguen". Se fueron dos semanas y lo mismo, pero esta vez no les di toda la semana a los muchachos, les di media semana, sacando de mis propios ahorros. Era a mediados del mes de noviembre y pues ya no había dinero. Según [que] se tenía que terminar primero el trabajo para que llegara todo el dinero. Estábamos pintando [...] unas paredes y ventanas de madera que se tenían que barnizar, eran como unas 100 ventanas. [El señor] me salió con la excusa de que habíamos echado a perder unas paredes, unas puertas y me dijo: “¿Qué dinero es el que estás reclamando? Al contrario, tú me sales debiendo” (Miguel, San Pablito Pahuatlán, 1 de agosto de 2013).

En la pasada década, Robert Smith reveló en una conferencia magistral que una parte importante de los nuevos edificios de la ciudad de Nueva York habían sido erigidos sobre trabajo impago de mexicanos. Smith les hizo saber a los trabajadores la posibilidad de que, a pesar de su condición de migrantes indocumentados, podían demandar a sus empleadores cobijándose en los mandatos de la Organización Internacional del Trabajo; sin embargo, ante el recelo de que al final del proceso fueran deportados, pocos denunciaron los abusos a que se habían enfrentado. La "fragilidad jurídica" (Izcara, 2010), que resulta de su condición de migrantes indocumentados, acrecienta el temor de organizarse para reclamar derechos y denunciar abusos de patrones y contratistas. A este miedo se suma la competencia feroz entre los trabajadores, que impide su reconocimiento como clase. Una vez más, Miguel narra su experiencia al respecto:

[...] faltando tres días para terminar el trabajo le dije [al americano] que no le trabajaba si no me daba el dinero. Pues con la misma finta de "si quieres no vayas, pero si no se termina el trabajo no hay dinero" y así me siguió diciendo. [...] Ya para terminar el trabajo, [...] nomás para hacer puros detalles, ya quedaba poco para terminar, pero, "si no se termina un trabajo por completo, a lo mejor no se recibe el dinero", es lo que pensé yo y fui con esa idea. Llego yo y ya está otro grupo de pintores, eran americanos, yo no los conocía. Cada quien va por su lado, eso es lo mismo que tenemos acá. Creo que nunca va a acabar esa mala manía de querer jalar agua cada quien para su molino. ¿Por qué? Porque si se encuentra un grupo de pintores con otro grupo de pintores, hasta ni para saludarse. Sienten que la competencia va a ser más difícil teniendo otro grupo de pintores (Miguel, San Pablito Pahuatlán, 1 de agosto de 2013).

La mayoría de estos trabajadores piensan que su condición de indocumentados prácticamente cancela las posibilidades de la organización sindical. Víctor, mexiquense de 38 años de edad y con más de nueve de residencia en Estados Unidos, refirió la existencia en Durham de una asociación de pintores guanajuatenses, integrada exclusivamente por trabajadores de ese origen, aun indocumentados. Sin embargo, Víctor considera que como la mayoría de quienes han Ilegado a Estados Unidos más recientemente, especialmente del centro y sur de México, no tienen papeles, es muy difícil, si no imposible, que se organicen sindicalmente por temor a ser deportados.

Martin (2012) señala que en los años 50 y 60 la construcción y la manufactura estuvieron asociadas con los llamados "trabajadores sindicalizados de cuello azul" que ganaban salarios por encima del promedio. Con solo el high school, carpinteros, trabajadores automotrices y del acero, representados por sindicatos, gozaron de un estilo de vida de clase media. En los 70 estas tendencias cambiaron, la participación de trabajadores sindicalizados en la construcción cayó de 40\% en aquellos años a 14\% en 2011; desde entonces los sindicatos han perdido la mayor parte de su poder en la construcción residencial, que es el grupo en el que se concentra la mayoría de los trabajadores mexicanos. Al respecto, Harvey (1988:172) anota que una de las consecuencias de la reconstruc- 
ción de focos de acumulación flexible en regiones que carecian de tradiciones industriales previas, como el sureste estadounidense, fue precisamente el menoscabo que sufrieron las organizaciones de los trabajadores. Además, como resultado del aumento de las redes de sub-contratación étnicas o familiares, que analizaremos en el siguiente apartado, este mismo autor (Harvey, 1998:177) ha advertido que luchar contra la explotación capitalista en la fábrica es muy diferente a luchar contra un padre o un tío que trabaja por encargo para el capital multinacional. Junto con Pacheco y Morfín (en prensa), podemos decir que:

Las nuevas formas de dominación sobre el trabajo en [Estados Unidos] están provocando una polarización de las clases trabajadoras que tienen que sortear sus deprimidas y flexibles condiciones de trabajo en medio de una competencia voraz por los precarios empleos entre una vasta estratificación de trabajadores diferenciados en torno a dos ejes: por un lado, su estatus legal y tiempo de residencia y, por otro, toda una serie de factores étnicos, culturales, lingüísticos, generacionales y de género, articulados en complejas formas de racismo, sexismo y segregación laboral en la sociedad estadounidense.

\section{EL RECLUTAMIENTO DE TRABAJADORES PAHUATECOS Y OTOMIIES}

A fines de los años 80, después de la promulgación de la Reforma de Inmigración y Acta de Control (IRCA, por sus siglas en inglés), a las visas $\mathrm{H} 2 \mathrm{~A}$-a través de las cuales la agricultura estadounidense se abastece de la mayor parte de la fuerza de trabajo que requiere- se añadieron las visas $\mathrm{H} 2 \mathrm{~B}$ para el empleo en los servicios; en la actualidad, tres cuartas partes de esas visas se otorgan a trabajadores mexicanos (Durand, 2006:54). En las redes electrónicas encontramos hoy en día docenas de anuncios en los que se ofrecen empleos en diversos sectores de la economía estadounidense, incluida la industria de la construcción, por medio de visas H2B, el siguiente es un botón de muestra:

\section{CONSTRUCCIÓN, AGRICULTURA, CAMPO - Hermosillo \\ Fecha de publicación: 02 Mayo 2012 \\ Nombre de la Compañía: immigration usa \\ Posición: Tiempo completo \\ SI ESTÁS INTERESADO EN TRABAJAR EN ESTADOS UNI- DOS LEGALMENTE CON VISA DE TRABAJO EN EL ÁREA DE LA CONSTRUCCIÓN Y LA AGRICULTURA COMUNICATE AL CELL $6622223944^{9}$}

No obstante, el reclutamiento de pahuatecos y otomíes en la construcción se da a través de redes de paisanos, parientes o conocidos, quienes "trabajan para patrones gringos" que les solicitan buscar trabajadores para, como se observa en el testimonio arriba anotado, realizar obras específicas en periodos acotados. Al respecto, Benencia, Herrera y Levine (2013:42-43) han señalado que los trabajadores migrantes en Estados Unidos son parte de "cuadrillas sombra", reclutados por contratistas o subcontratistas a través de redes sociales étnicas. Según Martin (2012), la industria de la construcción tiene unos pocos empresarios grandes y muchos pequeños: en 2007 había casi 730.000 establecimientos de la construcción con 7,3 millones de empleados, de acuerdo con el más reciente censo de la industria $80 \%$ de estos establecimientos tenía menos de 10 trabajadores. Rigoberto describe con meridiana claridad el funcionamiento de este patrón de organización del trabajo:
[...] Allá está la compañía que construye, dice Rigoberto. Entonces ahí van los contratistas americanos a agarrar el trabajo. [La compañía les da] un listado: [Les dicen:] "tengo una construcción de mil casas"; por lo regular son nada más cinco modelos. [Entonces] ya les dicen "este modelo vale tanto, te voy a dar 70.000 dólares". Ya ellos buscan a un subcontratista, o llega el subcontratista, [y le dicen]: "Tengo todo este tracker, [...] hazte tú esta hilera de casas, son como cincuenta, este modelo tiene un precio, este tiene otro precio". Es una cadena hasta que llegan a nosotros. Por ejemplo, a nosotros por hacer una casa, por hacer el ceiling sencillo del frente, nos daban ¿qué será? A mí me daban 800 dólares, [...] al cortador le daban 1.200. [Pero] primero una gran tajada para el subcontratista y así se van. Cuando yo estuve [en Durham] trabajé en el ceiling, cuando me fui para Las Vegas trabajé en el freimer en la construcción de casas de madera. [...] En Durham gana uno un promedio de 10 dólares, 15 dólares el que ya sabe cortar bien o más o menos. En Las Vegas, me dijeron "qué sabes" y [les dije] "sé hacer el ceiling, los barandales, adentro el freimer, bien pagado, yo llegué a ganar hasta 30 dólares por hora. Pero en Durham trabajé para los subcontratistas, en cambio en Las Vegas trabajé directamente para las compañías, por eso se gana más (Rigoberto, Pahuatlán de Valle, 13 de julio de 2011).

El incremento de la subcontratación ha sido explicado por diversos autores (Sassen y Smith, 1992; Canales, 1999, entre otros) como expresión de la polarización del mercado laboral, en el que junto a empleos estables y de altos ingresos, se ubican otros caracterizados por su informalidad y temporalidad, que han crecido a consecuencia de la expansión de la economía informal en muchas grandes ciudades estadounidenses y en los que se observa una fuerte presencia de hispanos, quienes, como los pahuatecos y sanpablitos, pueden ser reclutados y desechados en temporadas de contracción del sector. Al respecto, Harvey (1998:175) ha anotado que [...] la subcontratación organizada ofrece oportunidades para la formación de pequeñas empresas y, en algunos casos, permite que los viejos sistemas de trabajo doméstico, artesanal, familiar (patriarcal) y paternalista (del tipo del "padrino", del "gobernador" o de la mafia) revivan y florezcan como piezas centrales, y no ya como apéndices del sistema de producción.

Por otro lado, Levine y LeBarone (2011) han advertido que la demanda de trabajadores en la industria de la construcción del sureste estadounidense no sólo ha sido cubierta con fuerza de trabajo llegada directamente de más allá de la frontera sur, también se ha echado mano de trabajadores migrantes asentados en otras latitudes de Estados Unidos quienes se han desplazado por cuenta propia o enganchados por subcontratistas en búsqueda de mejores salarios. La carrera laboral de Rigoberto en Estados Unidos es un buen ejemplo de este carácter itinerante que lo llevó a desplazarse del sureste al oeste de la unión americana:

Durham es pequeño. [...] Las construcciones están en las orillas, por ejemplo; Chapell Hill, varias universidades buenas de los Estados Unidos. Duke [en donde estudian medicina y hay hospitales reconocidos]. Por eso ahí hay algo de trabajo, bueno yo trabajé en la construcción allá, en el ceiling. [...] Yo creo que [Carolina del Norte] está en crecimiento, se está modernizado casi todo, por eso había mucha demanda de trabajo ahí. [Bueno], entre comillas,
44 > Revista Márgenes N 13 Vol. 10 > Diciembre 2013: 40-48 Facultad de Arquitectura > Universidad de Valparaíso
$>$ ISSN electrónico 0719-4436 $>$ ISSN impreso 0718-4034 
porque también había mucha gente que, aun viviendo en Durham, sale a trabajar a Virginia, Carolina del Sur. [...] El o los que te consiguen el trabajo, por decir, el subcontratista, agarra un contrato en Sur Carolina y nos dice: "Pues nos tenemos que ir para allá un mes" o "hay 100 casas que agarré". [...] Ellos te pagan el hotel y todo, tú sigues ganando igual. Mucha gente [...] hace ahí su lugar de asentamiento. Yo, por ejemplo, estuve en Sur Carolina con otro primo ocho meses. Luego me regresé a Durham y de Durham me fui para Reno, Nevada, cerca de Las Vegas, de costa a costa casi, ahí fui a trabajar también en la construcción y me fue mucho mejor (Rigoberto, Pahuatlán de Valle, 13 de julio de 2011).

En su estudio sobre las trabajadoras mexicanas en el procesamiento de cangrejo azul en las costas rurales de Carolina del Norte, Maryland y Virginia, Griffith (2002:48) señala que las formas de reclutamiento de personal para trabajos estacionales particularmente onerosos, como es el caso aquí analizado, más que depender del mercado, dependen del poder. Desde esta perspectiva, junto con Griffith (2002:48), podemos decir que a través de las redes étnicas de reclutamiento que se tejen entre parientes, amigos y paisanos, pahuatecos y sanpablitos se disciplinan unos a otros, asegurando con ello el control de su fuerza de trabajo. Es importante señalar que aunque los ingresos de los sub-contratistas rebasan a los de sus trabajadores, permitiéndoles a algunos alcanzar mejores niveles de vida y lograr cierta acumulación, también ellos forman parte de esa "cadena" a la que alude Rigoberto y que su trabajo igualmente genera plusvalía para las grandes compañías constructoras. Esto último se manifiesta de manera contundente en la siguiente frase de Rubén, mexiquense de 38 años de edad, quien ha residido en Estados Unidos por más de 20 años y sub-contrata personal para la pintura: Nosotros no nos quedamos ni con el $50 \%$ de la riqueza que generamos (Rubén, Durham, NC, 9 de octubre de 2013).

\section{TRABAJAR SOBRE ANDAMIOS SIN RED DE PROTECCIÓN}

En Estados Unidos [las caídas en altura] representan una de las causas principales de los graves y mortales [accidentes] en el sector de la construcción. El análisis de 3.496 muertes ocurridas en la construcción entre 1985 y 1989 realizado por la Ocupational Safety and Health Administration (OSHA) muestra que el 33\% de las defunciones se deben a accidentes provocados por caídas en altura. Por otro lado, las deficiencias en las protecciones contra caídas en altura representan el mayor número de denuncias en OSHA y el costo de las lesiones supone en este país una cantidad superior a 5 billones de dólares USA anualmente (González y Cobo, 2011).

A pesar de estas escalofriantes cifras dadas a conocer por un grupo de investigadores de la Universidad Politécnica de Madrid, las riesgosas prácticas de algunas compañías constructoras y la corrupción que campea entre los inspectores del ramo, son experiencias cotidianas de los trabajadores otomíes y pahuatecos que se ven obligados a laborar en condiciones que ponen en peligro su vida en innumerables ocasiones. Trabajadores entrevistados recientemente en Durham consideran que la no utilización de implementos de seguridad y los consecuentes accidentes laborales son responsabilidad total de los trabajadores. En contraste con esta opinión, Rigoberto refiere que los trabajadores no usan esos artefactos pues ocasionan demora en sus labores y, por lo tanto, la merma de sus ingresos; además, como lo veremos enseguida, a diferencia de sus paisanos asentados en aquella ciudad de Carolina del Norte, Rigoberto opina que la presencia de los inspectores de OSHA en las obras no necesariamente garantiza el cumplimiento cotidiano de las normas de seguridad.

[...] nadie te inspecciona, dice Rigoberto. Hay un tipo de inspectores por parte de la ciudad [que] llegan a las construcciones y checan [...] todo [lo] instalado. Porque allá en Durham las construcciones sí son altas, de tres pisos, y tienes que andar en andamios de [un ancho como de 10 pulgadas], tienes que andar con tu arnés y todo, tus gafas, tu casco. Pero, desgraciadamente, [...] si trabajas así no le avanzas, también por eso hay muchos accidentes. [...] Lo que pasa es que también el arnés es un arma de doble filo, porque si tú quieres caminar rápido y [...] se te llega a atorar, te da un jalón y no te caes al suelo, pero te arrimas un buen... Muchos por eso no [los] usaban. Ya cuando vemos que llegaba la camioneta de la OSHA, ya el que está cortando se da cuenta y ya nos avisa o [si] va a venir supervisión ya nos avisa el propio americano [...] Es que así amarrado no puedes trabajar a gusto, [...] pero también es más riesgoso porque [...] una caída de esas puede ser mortal o quedan paralíticos (Rigoberto, Pahuatlán de Valle, 13 de julio de 2011).

El que los trabajadores migrantes indocumentados y los subcontratistas estén bajo presión para trabajar rápido, como lo observamos en el testimonio de Rigoberto, ha contribuido al aumento de los accidentes en el lugar de trabajo (Martin, 2012). Asimismo, es importante anotar que el trabajo en altura es realizado por quienes se han insertado a la industria de la construcción recientemente o por aquellos que no logran adquirir otras habilidades para pasar a oficios menos riesgosos, lo que abona al pago de menores sueldos en comparación con los que ganan quienes realizan otras actividades. Rigoberto, quien a pesar de haber permanecido varios años en la industria de la construcción, nunca pudo dejar de trabajar "por los cielos", refiere esas diferencias salariales:

[...] A cada persona [nos dicen:] "te voy a dar 800 a ti, 1.000 a ti porque eres el que sabe más”. Ellos te conocen y uno también [...] sabe lo que sabe [hacer]. [...] Yo estaba hasta abajo porque casi no trabajé mucho, a mí me daban 800, [...] mi amigo [y yo] nos subíamos a clavarlo todo en los andamios. [...] Él era el que sabía más, me decía: “no que aquí", porque son muchos cortes, de ángulos y caídas de los techos, entonces uno no sabe mucho de eso (Rigoberto, Pahuatlán de Valle, 13 de julio de 2011).

Un riesgo más para estos trabajadores está ligado al uso de solventes y substancias tóxicas, especialmente entre los pintores, quienes no usan cotidianamente mascarillas para protegerse. Son quienes se inician en esa actividad los que mayormente se exponen a esos riesgos, pues quienes cuentan con mayor experiencia procuran, en la medida de lo posible, no realizar trabajos que los expongan a esas substancias. Vale la pena señalar que los subcontratistas tienen la obligación de proveer a los trabajadores de seguros contra accidentes laborales: Rubén eroga 5.000 dólares anuales en seguros para los cinco o seis trabajadores que emplea; además, es él quien se encarga del transporte de los obreros y de proveerlos de las herramientas necesarias para la faena. 
COMO NO ME GUSTÓ EL ESTUDIO,

\section{ME TUVE QUE VENIR AL NORTE}

Reiterativamente se ha señalado (Canales, 2007; Smith, 2004; Cortés, 2004) que los bajos niveles salariales que devengan los trabajadores mexicanos en Estados Unidos, y específicamente de aquellos que se insertan en la industria de la construcción (Martin, 2012), están asociados a sus bajos grados de escolaridad: en 2012,43\% de los migrantes mexicanos entre 16 y 64 años de edad tenían menos de 10 años de escolaridad (BBVA, 2012). Aunque la relación baja escolaridad-bajos salarios que se ha establecido tiene un sustento real, desde mi punto de vista deja de lado factores que coadyuvan a las bajas percepciones de estos trabajadores, entre ellos, como se ha señalado en este texto, su fragilidad jurídica resultado de su condición de migrantes indocumentados y el ser parte de una minoría étnica. Así, podemos apreciar que aunque algunos hayan alcanzado mayores grados de escolaridad antes de migrar a Estados Unidos, los pahuatecos y otomíes, como el grueso de los trabajadores mexicanos en Estados Unidos, están condenados a ser esa "mano de obra de ejecución" a la que se refiere Iglesias (2012:46), que realiza trabajos sin ninguna calificación o saber productivo y que devenga bajos salarios. El caso de Rigoberto quien, a pesar de haber estudiado dos años de ingeniería y tener calificaciones como electricista, es ilustrativo de esta situación.

Las largas jornadas laborales, que pueden prolongarse hasta por 14 horas diarias seis días a la semana; el trabajo pesado y riesgoso en condiciones climáticas extremas, con temperaturas que en el verano pueden alcanzar más de $40^{\circ} \mathrm{C}$ y el fuerte desgaste físico que ello conlleva, prácticamente cancelan las posibilidades de estos trabajadores de continuar una carrera escolar o tomar clases de inglés. No obstante, algunos le quitan horas a sus periodos de descanso y se matriculan en cursos de inglés o en programas intensivos para culminar el high school. Oscar -joven mexiquense de 24 años de edad, que llegó a Durham cuando contaba con escasos 15 años, en donde ha trabajado desde aquel entonces como pintor - hace casi dos años decidió ocupar las noches para acudir a clases de inglés y del programa GED (General Educational Development), equivalente al high school, que ofrecen los Community College. Oscar piensa que cuando obtenga su diploma de GED y hable inglés podrá hacerse de un empleo fuera de la construcción y con ello logar mejores percepciones.

\section{A MANERA DE CONCLUSIÓN}

Siguiendo a diversos autores, he presentado algunas reflexiones en torno a las condiciones de la participación de trabajadores mexicanos en la industria de la construcción estadounidense. Los aportes de David Harvey $(1998 ; 2003)$ acerca de las transformaciones espaciales y la reorganización del trabajo en el contexto de la flexibilización del régimen de acumulación, los planteamientos de Sara Lara (1998) sobre la minorización de los indígenas en la agroindustria mexicana y el análisis de David Griffith (2002; 2012) en torno al reclutamiento de trabajadoras mexicanas en la industria procesadora de jaiba y a la industria de la construcción, me han permitido ordenar este acercamiento. Siguiendo una veta de indagación que se propone ir más allá del consabido tema del mercado de trabajo, mi propuesta de análisis intenta tomar en consideración esas "nuevas formas de proletarización" características de la actual fase de acumulación capitalista.
Desde esta perspectiva hemos podido observar que el carácter flexible de la fuerza de trabajo de pahuatecos y otomíes aumenta su vulnerabilidad y precariedad en tanto impide cualquier posibilidad de organización y enfrentar a los dueños de las empresas constructoras para las que laboran, a quienes, aún la mayoría de los subcontratistas, nunca llegan a conocer. En este último sentido, podemos decir junto con Harvey (1998:176-177) que [I]a conciencia de clase no surge en este caso de la relación de clase directa entre capital y trabajo, [...] se desplaza a un terreno mucho más confuso de conflictos inter-familiares y peleas por el poder dentro de un sistema familiar o de clan, de relaciones sociales jerárquicamente ordenadas [que son la base de las redes de subcontratación].

Asimismo, hemos visto que el crecimiento exponencial de la participación de trabajadores mexicanos en la industria de la construcción estadounidense se dio en el contexto de la "burbuja del mercado de casas" entre 2002 y 2005 (Byun, 2010). La progresiva demanda de trabajadores en la construcción de casas - donde, en ese mismo periodo, el empleo se incrementó $26,6 \%$, cifra considerablemente superior al $15,4 \%$ de crecimiento que se dio en todo el sector- fue satisfecha en buena medida con migrantes hispanos indocumentados. Hecho que coadyuvó, por un lado, a la depresión de los salarios y, por otro, a la desarticulación de las organizaciones sindicales (Martin, 2012).

Todo lo cual, como observamos en este trabajo, abonó al aumento exponencial de las ganancias de las grandes empresas constructoras, las que, al cobijo de créditos hipotecarios blandos y valiéndose de una abundante mano de obra barata e indocumentada, inundaron el mercado inmobiliario, generando a la postre una crisis de fluidez que golpeó fuertemente la economía estadounidense y que redundó en el desempleo de miles de trabajadores de la industria de la construcción -entre mayo de 2006 y mayo de 2010 el empleo en la construcción residencial cayó 42\% (Cover, 2011)-. Quienes han "resistido" en el "gabacho" lo han hecho a costa de ver mermados sus ingresos y acrecentadas sus jornadas laborales. Las extremas condiciones de explotación a que son sometidos han tenido como corolario el deterioro de su salud, tema que no fue analizado aquí, pero que es de fundamental importancia en aras del cabal entendimiento de las "nuevas formas de proletarización".

\section{BIBLIOGRAFÍA}

BBVA SERVICIO DE ESTUDIOS ECONÓMICOS DEL BBVA (2012) Situación migración México. Noviembre 2012. Análisis económico. México: Fundación BBVA Bancomer.

BENENCIA R., HERRERA F. y LEVINE E. (2012) “Introducción”. En R. Benencia, F. Herrera y E. Levine (coords.), Ser migrante latinoamericano, ser vulnerable, trabajar precariamente (páginas 9-34). México: Anthropos.

BYUN K. J. (2010) "The US Housing Bubble and Bust: Impacts on Employment". En Monthly Labor Review, December 2010, páginas 3-17.

CANALES A. (2007) "Los inmigrantes latinoamericanos en Estados Unidos: inserción laboral con exclusión”. En Alejandro I. Canales (ed.), Panorama actual de las migraciones en América Latina (páginas 81-116). México: Universidad de Guadalajara, Asociación Latinoamericana de Población.
46 > Revista Márgenes N 13 Vol. 10 > Diciembre 2013: 40-48 Facultad de Arquitectura > Universidad de Valparaíso
> ISSN electrónico 0719-4436 > ISSN impreso 0718-4034 
(1999) "Migración internacional y flexibilidad laboral en el contexto de NAFTA". En Mexico and the World, Vol. 4, № 1 (Winter 1999). Recuperado de http://www.profmex.org/ mexicoandtheworld/volume4/1winter99/migracion_internacional.html

CONNOLLY P. (2007)“The Mexican Construction industry at the Start of the Twenty-first Century: trends and outlooks". En Tecnología y Construcción 23 (2), páginas 51-74.

CORTÉS SÁNCHEZ S. (2004) "Emigración de los poblanos en el decenio de los noventa", en R. Cortina y M. Gendrau (cords.) Poblanos en Nueva York. Migración rural, educación y bienestar (páginas 167-186). México: Universidad Iberoamericana Puebla.

COVER B. (2011) "Construction Employment: A Vissual Essay". En Monthly Labor Review, November: 3-17.

D'AUBETERRE BUZNEGO M. E. y RIVERMAR PÉREZ M. L. (coords.) (2011) Migración internacional en la Huasteca poblana. Actores y procesos. México: BUAP.

(En prensa) "Aquí en Pahuatlán la migración al norte ya se acabó". Auge y contención de un flujo migratorio en la Sierra Norte de Puebla en tiempos de recesión económica global". En M. E. D'Aubeterre y M. L. Rivermar (coords.), Migración acelerada, crisis de la economía estadounidense y retornos en cuatro localidades del estado de Puebla.

D'AUBETERRE BUZNEGO M. E., RIVERMAR PÉREZ M. L. y BINFORD L. (En prensa) "Migración acelerada y retorno en cuatro localidades del estado de Puebla". En M. E. D’Aubeterre y M. L. Rivermar (coords.), Migración acelerada, crisis de la economía estadounidense y retornos en cuatro localidades del estado de Puebla.

DURAND J. (2006) Temas de migración. Programas de trabajadores temporales. Evaluación y análisis del caso mexicano. México: SEGOB, CONAPO.

GONZÁLEZ GARCÍA M. N. y COBO ESCAMILLA A. (2011) “El riesgo de caída en altura". En Formación de Seguridad Laboral, 68, junio de 2011. Recuperado de http://www.seguridadlaboral.es/prevencion/altura/el-riesgo-de-caida-en-altura

GRIFFITH D. (2002) “El avance de capital y los procesos laborales que no dependen del mercado". En Relaciones 90, primavera 2002, vol. XXIII, páginas 19-53.

HARVEY D. (1998) La condición de la postmodernidad. Investigación sobre los orígenes del cambio sociocultural. Buenos Aires: Amorrortu editores.

(2003) The New Imperialism. New York: Oxford University Press Inc.

IGLESIAS MARTÍNEZ J. (2012) “¿Un nuevo proletariado étnico en los países desarrollados? El caso de los trabajadores ecuatorianos en la región madrileña". En R. Benencia, F. Herrera y E. Levine, Ser migrante latinoamericano, ser vulnerable, trabajar precariamente (páginas 37-58). México: Anthropos.

IZCARA PALACIOS S. P. (2010) “La adicción a la mano de obra ilegal: jornaleros tamaulipecos en Estados Unidos". En Latin American Research Review, 45, núm. 1, páginas 55-75.
KOCHHAR R. (2010) “Latino Labor Report 2008. Construction Reverses Job Growth for Latinos", June 2008. Recuperado de www.pewhispanic.org/2008/06/04/latino-labor-report2008-construction-reverses-job-growth-for-latinos

LARA FLORES S. M. (1998) Nuevas experiencias productivas y nuevas formas de organización flexible del trabajo en la agricultura mexicana. México: Procuraduría Agraria, Juan Pablos Editor.

LEVINE E. y LEBARON A. (2011) "Immigration Policy in the South Eastern United States: Potential for Internal Conflict". En Norteamérica. Revista Académica del CISAN-UNAM, año 6, número especial, páginas 5-32.

MARTIN P. (2009) "Recession and Migration: A New Era for Labor Migration". En International Migration Review 43 (3), páginas 671-691.

(2012) "Migration and Competitiveness in US Construction and Meatpacking", August 24, 2012. Recuperado de migrationfiles.ucdavis.edu/uploads/rs/files/2012/9/clip/ martin-us-construction-and-meatpacking.pdf

PACHECO C. y MORFIN A. (En prensa) "Reserva latente de mano de obra, crisis global y contención de un flujo migratorio acelerado a Nueva York. El caso de Huaquechula". En M. E. D’Aubeterre y M. L. Rivermar (coords.), Migración acelerada, crisis de la economía estadounidense y retornos en cuatro localidades del estado de Puebla.

PARRA RUIZ J. M. y GÁMEZ FRÍAS E. (2012) "Situación de la fuerza de trabajo mexicana en Estados Unidos". En R. Benencia, F. Herrera y E. Levine (coords), Ser migrante latinoamericano, ser vulnerable, trabajar precariamente (páginas 113-136). México: ANTHROPOS, UAM-I.

REINA CORONA C. y LUQUE GONZÁLEZ J. R. (1992) "Cambios recientes en los patrones migratorios a la Zona Metropolitana de la Ciudad de México, ZMCM". En Estudios Demográficos y Urbanos, vol. 7, n 2-3 (20-12), mayo-dic. 1992, páginas 575-586.

RUBIO B. (1994) “La agricultura mundial de fin de siglo: hacia un Nuevo orden agrícola internacional". En México y la globalización (páginas 63-85). Cuernavaca: Universidad Nacional Autónoma de México, CRIM.

SMITH R. (2004) "Imaginando los futuros educativos de los mexicanos en Nueva York". En R. Cortina y M. Gendrau (coords.) Poblanos en Nueva York. Migración rural, educación y bienestar (páginas 87-112). México: Universidad Iberoamericana Puebla.

TINLEY A. (2008) “Jóvenes mexicanos en el sudeste de Estados Unidos: perspectivas y opciones para seguir estudiando". En E. Levine (ed.) La migración y los latinos en Estados Unidos. Visiones y conexiones (páginas 295-320). México: UNAM, CISAN.

WHITE T. (2001) Durham. Where Visions Become Reality. Riverben Books.

NOTAS

1 Organizaciones: CPWR - The Center for Construction Research and Training “Trabajadores hispanos en la construcción y otras in- 
dustrias", en The Construction Chart Book, The Center to Protect Workers' Rights, 16.

2 "Afectará a trabajadores mexicanos caída en el sector de la construcción de EU", Periódico La Jornada, 8 de agosto de 2008 , versión electrónica.

3 Los condados de Durham, Raleigh y Chapel Hill forman el triángulo financiero de Carolina del Norte, cuyos orígenes se remontan a fines del siglo XIX, cuando las familias Spaulding, Merrick, y Moore fundaron en 1898 la Mutual Life Insurance Company, que fue precursora de Mechanics and Farmers Bank y de Mutual Community Savings and Loan, empresas que llevaron a Durham a alcanzar notoriedad como el Black Wall Street of America (White, 2001).

4 En 1958 fue creado el Instituto Mexicano del Café (INMECAFE) cuyo objetivo central era promover y difundir los sistemas más convenientes de cultivo, beneficio e industrialización del aromático. En 1973 el INMECAFE inició un esquema organizativo básico para financiar a la cafeticultura nacional poniendo en marcha una fuerte campaña para agrupar a los productores en las llamadas unidades económicas de producción y comercialización (UEPC). Bajo este esquema los productores miembros recibían anticipos bajo un compromiso solidario donde todos debían liquidar sus adeudos individuales mediante la entrega de una parte de la cosecha que sería beneficiada en las instalaciones del INMECAFE. Por medio de este mecanismo se habilitó a tres cuartas partes de los productores cafetaleros del país. En 1989 se da un severo desplome de precios por la suspensión del sistema de cuotas, lo que provocó serios problemas de liquidez entre los exportadores al verse obligados a vender el café oro a precios más bajos a los que se habían venido pagando. Un gran número de beneficiadores quedaron sin capital para operar los ciclos siguientes, perjudicando principalmente a medianos y grandes beneficiadores. A esto se aunaron las severas heladas de 1989 en las regiones cafetaleras de Puebla, San Luis Potosí y algunas partes altas de Veracruz, desplomándose la producción $11 \%$ de la producción nacional, lo que contribuyó a incrementar los problemas de capacidad de pago de los productores. En 1989 se propone un cambio estructural del INMECAFE que incluía la transferencia mediante la venta al sector social de los beneficios e instalaciones de almacenamiento para que los productores minifundistas vendieran café oro en mejores condiciones a través de sus organizaciones. http://www.contactopyme. gob.mx/guiasempresariales/guias.asp?ins=85\&s=14 (Última consulta 10 de septiembre de 2013) (D'Aubeterre y Rivermar, 2011).

5 Una de las obligaciones para quienes se interesan en laborar en este sector es prepararse en cursos que la cámara de la construcción estadounidense o los sindicatos ofrecen, lo que los califica como "trabajadores autorizados". Por supuesto, esta obligación no pesa sobre los trabajadores indocumentados.

6 Recuperado de http://www.jobbankusa.com/spanish/career_employment/construction_laborers/salary_wages_pay.html

7 Estas diferencias se deben, en parte, a que muchos de los nuevos trabajadores nativos se inician en este último grupo y, probablemente, no han logrado la respectiva autorización para laborar en la industria de la construcción, lo que los deja con poco poder de negociación (Martin, 2012).
8 Recuperado de http://www.obrasweb.mx/construccion/2012/12/ 20/china-y-eu-encabezan-la-recuperacion-de-la-industria

9 http://hermosillo.olx.com.mx/construccion-agricultura-campo-iid367717395 (Última consulta 27 de septiembre de 2013). 